\title{
OTIMIZAÇÃO DA EXTRAÇÃO DE ANTOCIANINAS PRESENTES NO FEIJÃO-PRETO E IMPREGNAÇÃO DO EXTRATO EM MATRIZ POLIMÉRICA NATURAL PARA USO COMO INDICADOR DE pH
}

\author{
Chalder Nogueira Nunesa,*,®, Aline Bortolanza Jansen ${ }^{a}$ e Sueli Pércio Quináia ${ }^{a}$ \\ a'Departamento de Química, Universidade Estadual do Centro-Oeste, 85040167 Guarapuava - PR, Brasil
}

Recebido em 23/06/2021; aceito em 27/08/2021; publicado na web em 22/09/2021

\begin{abstract}
OPTIMIZATION OF THE EXTRACTION OF ANTHOCYANINS PRESENT IN BLACK BEANS AND IMPREGNATION OF THE EXTRACT IN NATURAL POLYMERIC MATRIX FOR USE AS A pH INDICATOR. In this work, a method of extracting natural indicators, anthocyanins, present in black beans was optimized. The best extraction condition was obtained with $50 \mathrm{~g}$ of beans and $93 \mathrm{~g}$ of water, under agitation at $150 \mathrm{rpm}$, at a temperature of $40{ }^{\circ} \mathrm{C}$ for $24 \mathrm{~h}$. The wavelengths of greatest absorption for the indicator in its acidic and basic form were $523 \mathrm{~nm}$ and $620 \mathrm{~nm}$ respectively and these wavelengths were used to determine the pKa of the indicator. At least three pKa values were observed: 1.9; 7.2 and 10.7. A simplified condition for anthocyanins extraction, the same amount of water, tap water in these case, and beans kept together for $12 \mathrm{~h}$ without agitation and temperature control, was also evaluated. Both extracts were impregnated with qualitative filter paper, coffee filter paper and cotton buds and the materials impregnated with the indicator were tested with solutions of $\mathrm{HCl}$, vinegar, $\mathrm{NaOH}$ and milk of magnesia. A comparison between the impregnated material and a universal $\mathrm{pH}$ indicator paper using buffer solutions $\mathrm{pH}$ 4.0, 7.0, 10.0 and 11.2 proved the applicability of the developed material since it presented adequate distinction in its color for the different $\mathrm{pH}$ conditions.
\end{abstract}

Keywords: anthocyanins; black bean; chemistry teaching.

\section{INTRODUÇÃOO}

A experimentação para o ensino de Química mostrou-se de grande importância para a construção de conhecimentos tanto em alunos do ensino básico quanto do superior, tendo sua importância citada até mesmo em documentos oficiais para o ensino básico. ${ }^{1,2}$ Para Guimarães "a experimentação pode ser uma estratégia eficiente para a criação de problemas reais que permitam a contextualização e o estímulo de questionamentos de investigação", desta forma, colaborando para despertar o interesse do aluno sobre o tema e facilitar a aprendizagem. ${ }^{3}$

Embora o papel da experimentação no ensino de Química, com o objetivo de relacionar teoria e prática, seja indubitavelmente reconhecido, é fato que nem todas as escolas dispõe de laboratórios adequados, bem como de materiais e reagentes químicos necessários para aulas experimentais. Sendo assim, o uso de materiais e experimentos alternativos é recomendado nestas situações, inclusive pelos livros didáticos e outras obras, tais como o livro "Experimentos de Química com materiais domésticos" de Sônia Hess. ${ }^{4}$ Essas alternativas permitem a experimentação em condições não ideais sem perder a essência e qualidade da atividade. Para os professores do ensino básico essa é uma saída à falta de laboratórios e materiais, para os futuros professores, alunos das licenciaturas, tal conhecimento permite a eles produzirem futuros instrumentos para o ensino.

Dentre todos os experimentos usualmente realizados no ensino médio, a determinação da acidez ou basicidade de soluções e suspensões é frequente. Esses experimentos são relativamente simples, podendo ser executados com materiais domésticos, como vinagre, água sanitária, refrigerantes, sucos, etc. Para a identificação de soluções ácidas ou básicas podem ser empregados indicadores visuais de $\mathrm{pH}$, substâncias orgânicas que mudam de cor em função do $\mathrm{pH}$ do meio. ${ }^{5}$ Frequentemente os clássicos fenolftaleína, papel tornassol, papel indicador universal e pHmetros são utilizados para essa finalidade. Porém, mesmo esses indicadores não estão

*e-mail: chaldernunes@gmail.com sempre disponíveis, ou então, pretende-se realmente apresentar indicadores alternativos de $\mathrm{pH}$ a fim de explicar seu funcionamento, equilíbrio químico, funções orgânicas, etc. Dessa forma, o emprego de indicadores obtidos a partir de repolho roxo, ${ }^{6}$ feijão-preto, ${ }^{7}$ cenoura preta, ${ }^{8}$ flores,${ }^{79}$ beterraba ${ }^{10}$ e frutas ${ }^{5,11}$ é frequente. Além das finalidades didáticas, indicadores naturais de $\mathrm{pH}$ vêm recentemente recebendo novas aplicações. Etxabide e colaboradores avaliaram o uso de indicadores extraídos da curcuma (Curcuma longa L.), da beterraba (Beta vougaris L.) e da cenoura preta (Dacus carota L.) como indicadores de qualidade em alimentos uma vez que as atuais etiquetas de validade não fornecem informações reais sobre o estado do alimento. Os extratos obtidos da beterraba e da cenoura preta, contendo os princípios ativos benanina e antocianina respectivamente, apresentaram adequada estabilidade após 28 dias de estocagem e uma boa resposta à variação de $\mathrm{pH} .{ }^{12}$ Sani e colaboradores desenvolveram um filme de nanofibras de metilceluse/quitosana e antocianinas extraídas de bérberis para ser empregado como indicador de frescor em carnes. O material desenvolvido apresentou boas respostas à variação de $\mathrm{pH}$ e presença de gás amônia podendo ser utilizado como indicador inteligente em tempo real para o monitoramento de carnes e frutos do mar. ${ }^{11}$

Muitos desses indicadores naturais (In) possuem como substâncias ativas, responsáveis pela mudança de coloração, compostos conhecidos como antocianinas. ${ }^{13,14}$ As antocianinas são pigmentos naturais de plantas, solúveis em água e pertencentes à classe de compostos fenólicos conhecidos como flavonoides. ${ }^{15}$ Esses compostos, assim como indicadores de $\mathrm{pH}$ comerciais, possuem colorações diferentes para a sua forma ácida (HIn) e básica (In-) e, por serem ácidos ou bases fracas que coexistem em um equilíbrio químico, seu Kapode ser determinado experimentalmente, bem como seu pKa. ${ }^{16}$ Quando a concentração do In na forma ácida se iguala à concentração na forma básica, $[\mathrm{HIn}]=\left[\mathrm{In}^{-}\right]$, pode-se determinar o pKa do In e é próximo deste ponto que é possível notar a mudança na coloração da solução.

Esses indicadores naturais, como os obtidos do feijão-preto e do repolho roxo, são de fácil extração e utilização, porém os extratos 
possuem um tempo de vida relativamente curto, devido à degradação natural, uma vez que, frequentemente, são obtidos extratos aquosos. No entanto, extratos alcoólicos podem ter seu tempo de vida estendido. Mesmo que extratos aquosos sejam obtidos, a utilização de soluções não é tão prática quanto o papel tornassol. Essas constatações foram feitas durante a otimização do procedimento proposto no presente trabalho. Uma alternativa a esses limitantes é a impregnação das antocianinas em materiais sólidos, aumentando assim o tempo de vida do indicador, bem como sua praticidade. Terci e Rossi fizeram extratos etanólicos (1:3) de frutas e produziram papéis indicadores por meio da imersão de papel filtro qualitativo nas soluções. Segundo os autores, ambas as formas dos indicadores apresentaram resultados satisfatórios para a diferenciação entre soluções ácidas e básicas e até mesmo para estimar o valor do $\mathrm{pH} .^{5}$

Sendo assim, frente a necessidade real por indicadores de $\mathrm{pH}$ de fácil utilização em locais que não dispõe de infraestrutura, materiais específicos e a possibilidade de melhorar os já conhecidos indicadores naturais utilizados para fins didáticos, o presente trabalho propôs a otimização da forma de extração das antocianinas presentes no feijão-preto, matéria prima facilmente encontrada, por meio de um planejamento fatorial para ser utilizado como indicador de $\mathrm{pH}$. Além disso, a aplicação do indicador em sua forma líquida e impregnada em diferentes matrizes poliméricas foi também avaliada. Neste artigo também é apresentado um estudo para a determinação do pKa do indicador proposto empregando espectroscopia de absorção molecular por UV-visível.

\section{PARTE EXPERIMENTAL}

\section{Materiais e reagentes}

Os equipamentos utilizados neste trabalho foram: um pHmetro Hanna com resolução $0,01 \mathrm{pH}$, calibrado com soluções tampão Hanna HI 7004 (pH 4,01 \pm 0,01) e HI 7004 (pH 7,01 $\pm 0,01$ ), utilizado para os ajustes do $\mathrm{pH}$ das soluções dos indicadores; uma incubadora Tecnical modelo TE-420 para a preparação dos extratos; e um espectrofotômetro UV-visível de duplo feixe - Shimadzu com cubetas de quartzo utilizado para acompanhar os extratos em termos de intensidade de absorbância relacionada à concentração dos componentes da amostra.

Ajustes de $\mathrm{pH}$ foram realizados com soluções de hidróxido de sódio $(\mathrm{NaOH})$ e ácido clorídrico $(\mathrm{HCl}) 5 \mathrm{~mol} \mathrm{~L}^{-1}$. O indicador foi depositado em matrizes sólidas e para tal utilizaram-se folhas de papel sulfite A4 brancas, papel-filtro para café, papel-filtro qualitativo, algodão e hastes flexíveis de algodão. Os materiais indicadores preparados foram testados com as soluções $1 \mathrm{~mol} \mathrm{~L}^{-1}$ de $\mathrm{NaOH}$ e $\mathrm{HCl}$ e com produtos comerciais, sendo eles: Solução de ácido clorídrico a 33\% (ácido muriático), solução de ácido acético a 4\% (vinagre), hidróxido de sódio a 50\% (soda cáustica) e uma suspensão de hidróxido de magnésio $\left(\mathrm{Mg}(\mathrm{OH})_{2}\right)$ a $85,5 \mathrm{mg} \mathrm{mL}^{-1}$ (leite de magnésia). Testes de comparação entre o extrato de feijão-preto, os materiais indicadores produzidos e um papel indicador de $\mathrm{pH}$ universal (comercial) foram realizados com soluções tampão Biotec (pH 4,0, 7,0 e 10,0) assim como uma solução tampão de hidróxido de amônio $\left(\mathrm{NH}_{4} \mathrm{OH}\right)($ Biotec $) /$ cloreto de amônio $\left(\mathrm{NH}_{4} \mathrm{Cl}\right)$ (Synth) $(\mathrm{pH} \mathrm{11,2)}$.

\section{Desenvolvimento metodológico}

O processo de extração das antocianinas presentes no feijão foi avaliado por meio de um planejamento fatorial $2^{3}$, no qual foram empregados os fatores tempo de extração, solvente e temperatura em dois níveis com um ponto central. A temperatura de extração máxima avaliada foi de até $40^{\circ} \mathrm{C}$, para garantir a estabilidade térmica das antocianinas. ${ }^{17}$ Para esse estudo empregou-se a massa de $50 \mathrm{~g}$ de feijão e $93 \mathrm{~mL}$ de solvente, totalizando $150 \mathrm{~mL}$ do frasco de extração, a mistura foi deixada em agitação a $150 \mathrm{rpm}$. Embora a literatura aponte o uso de soluções etanólicas com $\mathrm{HCl}$ a $1 \%$ para uma extração completa das antocianinas em plantas, ${ }^{9,13}$ no presente trabalho foram avaliados o álcool etílico a $70 \%$ e a água destilada. Esses solventes podem ser facilmente encontrados nas escolas de ensino médio e a reprodução da forma de extração facilmente realizada sem riscos aos alunos. O planejamento fatorial está apresentado na Tabela 1.

Tabela 1. Planejamento fatorial $2^{3}$ para otimização do processo de extração das antocianinas presentes no feijão

\begin{tabular}{cccc}
\hline Experimento & $\begin{array}{c}\text { Tempo de } \\
\text { extração (h) }\end{array}$ & Solvente & $\begin{array}{c}\text { Temperatura } \\
\left({ }^{\circ} \mathrm{C}\right)\end{array}$ \\
\hline 1 & 2 & álcool 70\% & 40,0 \\
2 & 2 & álcool 70\% & 25,0 \\
3 & 24 & álcool 70\% & 40,0 \\
4 & 24 & água destilada & 40,0 \\
5 & 13 & álcool 70\% & 32,5 \\
6 & 24 & água destilada & 25,0 \\
7 & 2 & água destilada & 25,0 \\
8 & 13 & água destilada & 32,5 \\
9 & 24 & álcool 70\% & 25,0 \\
10 & 2 & água destilada & 40,0 \\
\hline
\end{tabular}

Após a escolha da melhor condição de extração das antocianinas, análises prévias do extrato em $\mathrm{pH}$ ácido, neutro e básico foram realizadas para determinar os comprimentos de onda com maior diferença na absorbância (Abs) entre o indicador na sua forma ácida e básica. A determinação dos valores de $\mathrm{pKa}$ do indicador foi realizada graficamente utilizando estes comprimentos de onda. A determinação do pKa baseou-se na equação de Henderson-Hasselbalch (Equação 1). De acordo com a lei de Beer, a concentração da espécie absorvente é proporcional à sua absorbância. Assim, monitorando a absorbância em um determinado comprimento de onda $(\lambda)$ em função da variação do $\mathrm{pH}$ é possível determinar o valor do $\mathrm{pKa}$ do indicador. ${ }^{18}$ Neste trabalho, escolheu-se determinar o pKa por meio da forma gráfica da Abs em função do $\mathrm{pH}$ e dos cálculos da primeira e segunda derivadas. ${ }^{18}$ Soluções de ácido clorídrico e hidróxido de sódio $5 \mathrm{~mol} \mathrm{~L}^{-1}$ foram empregadas para ajustar o $\mathrm{pH}$ do extrato.

$$
p K a=p H+\log \frac{[H I n]}{\left[\mathrm{In}^{-}\right]}
$$

Embora as condições otimizadas de extração tenham proporcionado bons resultados, uma forma alternativa de extração foi também avaliada empregando as mesmas quantidades de feijão e água, porém por 12 horas com água da torneira, sem controle de agitação e temperatura (condições simplificadas de extração), sendo essas condições mais fáceis de serem realizadas em escolas. Comprovada a eficácia dos extratos líquidos como indicador de $\mathrm{pH}$, foram conduzidos experimentos de deposição dos indicadores em matrizes orgânicas poliméricas. A ideia de depositar o indicador sobre uma superfície sólida surgiu após uma aula experimental, na qual foi utilizado o extrato de feijão-preto e esse manchou o jaleco do professor. A mancha persistiu alguns dias e quando o jaleco foi lavado, percebeu-se que o indicador continuava funcionando adequadamente, devido a sua reação com o sabão que possui caráter básico. Nesse momento, percebeu-se a praticidade e a estabilidade do indicador depositado sobre a celulose. Inicialmente, tiras de papel sulfite (A4) 
foram mergulhadas nos extratos e mantidas sob agitação manual por 5 minutos. Em seguida, as tiras foram retiradas e levadas à secura em temperatura ambiente e ao abrigo da luz. $\mathrm{O}$ mesmo procedimento foi realizado com papel-filtro qualitativo, papel-filtro para café e com algodão. Ácido clorídrico $\left(1 \mathrm{~mol} \mathrm{~L}^{-1}\right)$, vinagre (ácido acético a $4 \%$ ), hidróxido de sódio $\left(1 \mathrm{~mol} \mathrm{~L}^{-1}\right)$ e leite de magnésia (suspensão de hidróxido de magnésio a $85,5 \mathrm{mg} \mathrm{mL}^{-1}$ ) foram utilizados para avaliar a resposta dos materiais indicadores. Também foram utilizadas nas hastes com algodão produtos comerciais usados para limpeza, contendo solução de ácido clorídrico (popularmente conhecido como ácido muriático) e hidróxido de sódio (popularmente conhecido como soda cáustica), uma vez que são produtos normalmente utilizados em experimentos didáticos de ácidos e bases.

Os materiais indicadores produzidos, tanto com o extrato obtido nas condições otimizadas de extração, quanto com o obtido nas condições simplificadas de extração, foram comparados com um papel indicador de $\mathrm{pH}$ universal. Para tanto, foram pingadas nas soluções de extrato (diluído por um fator de dois) e nos materiais indicadores produzidos com papel-filtro qualitativo, papel-filtro de café e hastes de algodão duas gotas das soluções tampão pH 4,0, 7,0, 10,0 e 11,2.

\section{RESULTADOS E DISCUSSÃO}

Para aprimorar o processo de extração das antocianinas presentes no feijão-preto foram realizados 10 experimentos apresentados no planejamento fatorial, descrito na Tabela 1. Os extratos obtidos foram comparados por meio de uma leitura no equipamento de espectrofotometria UV-Vis na faixa de comprimentos de onda entre 300 e $1100 \mathrm{~nm}$. A Figura 1(a) apresenta o gráfico dos efeitos obtidos com os resultados do planejamento fatorial. Maiores inclinações significam maior influência do fator na extração. Dessa forma, percebeu-se que o solvente, em especial a água, apresentou melhores resultados na extração. O tempo de extração também foi importante, seguido pela temperatura com menor influência. Na Figura 1(b) estão apresentados diversos espectros, cada um deles correspondente a um experimento do planejamento fatorial (Tabela 1). Foram utilizados $1 \mathrm{~mL}$ de extrato de feijão e $3 \mathrm{~mL}$ de água para a leitura no espectrofotômetro. $\mathrm{O}$ critério de escolha para a melhor condição de extração das antocianinas foi a intensidade da absorbância relacionada com a concentração das espécies em solução. Como o experimento 4, extração com água por 24 horas a $40^{\circ} \mathrm{C}$, foi a condição com maior absorbância demonstrada no espectro, esta foi escolhida para os próximos estudos.

O extrato obtido pela condição otimizada foi então submetido a uma variação de $\mathrm{pH}$ para avaliar sua mudança de coloração e determinação dos picos de maior intensidade de absorbância para as condições de soluções ácidas e básicas. A Figura 2(a) apresenta uma foto dos extratos em meio ácido ( $\mathrm{pH}$ 2,2 ajustado com solução de $\mathrm{HCl}, 5 \mathrm{~mol} \mathrm{~L}^{-1}$ ), em pH natural do extrato (pH 5,8) e básico ( $\mathrm{pH} 9,0$ ajustado com solução de $\mathrm{NaOH}, 5 \mathrm{~mol} \mathrm{~L}^{-1}$ ). A coloração original do extrato aproxima-se de um roxo acinzentado, entretanto, em meio ácido assume uma coloração vermelha e em meio alcalino a cor da solução torna-se verde. As soluções apresentadas na Figura 2(a) foram diluídas a 50\% com água destilada para melhor visualização das cores. A Figura 2(b) apresenta os espectros para cada uma das soluções. As linhas apresentadas no gráfico foram representadas na mesma cor das soluções em cada pH para facilitar a visualização. Para a solução com o $\mathrm{pH}=5,8$, original do extrato, observa-se um máximo de absorbância pequeno em $600 \mathrm{~nm}$, por outro lado, no $\mathrm{pH}$ ácido, pode-se notar a presença de um pico bem intenso em $523 \mathrm{~nm}$. Do mesmo modo, em $620 \mathrm{~nm}$ surge um máximo de absorbância na banda para o pH 9,0. Dessa forma, esses comprimentos de onda onde ocorrem os máximos de absorbância do indicador em sua forma ácida (523 nm) e em sua forma básica $(620 \mathrm{~nm})$ foram utilizados para a determinação do pKa das antocianinas. Nota-se que em meio ácido o indicador encontrase protonado (HIn) e nesta forma o indicador absorve a radiação emitida pela fonte do espectrofotômetro, no $\lambda=523 \mathrm{~nm}$. Por outro lado, à medida que o pH vai aumentando, a [HIn] vai diminuindo e dando lugar à forma desprotonada do indicador $\left(\mathrm{In}^{-}\right)$a qual possui absorbância máxima em $\lambda=620 \mathrm{~nm}$.

Determinados os $\lambda$ de maior absorbância para HIn e In $^{-}$, prepararam-se soluções na faixa de pH entre 0,01 e 13,15. A avaliação da absorbância das soluções em diferentes valores de $\mathrm{pH}$ permitiu a determinação do pKa do indicador. A Figura 3(a) apresenta soluções bem diluídas (oito vezes) dos extratos em quase todos os pontos de $\mathrm{pH}$ avaliados por espectrofotometria. Pontos mais próximos de $\mathrm{pH}$ foram avaliados na faixa ácida entre 0,01 a 6,10 para melhor definição dos gráficos e assertividade na determinação do valor de pKa (Figura 3(b)).

Na Figura 3(a) é possível observar uma variação grande na tonalidade da coloração do indicador em função da variação do $\mathrm{pH}$ do meio. Nota-se que a coloração da solução foi do vermelho ao verde e em seguida ao castanho. Essa variação permitiu uma estimativa do valor do $\mathrm{pH}$ da solução e, além disso, para fins didáticos, cores vívidas, distintas e chamativas tendem a motivar os alunos em aulas experimentais. Vale ressaltar que as soluções apresentadas nessas imagens sofreram uma diluição de oito vezes do extrato original para permitir a leitura no espectrofotômetro sem estourar a escala de absorbância. Dessa forma, a coloração original dos extratos é
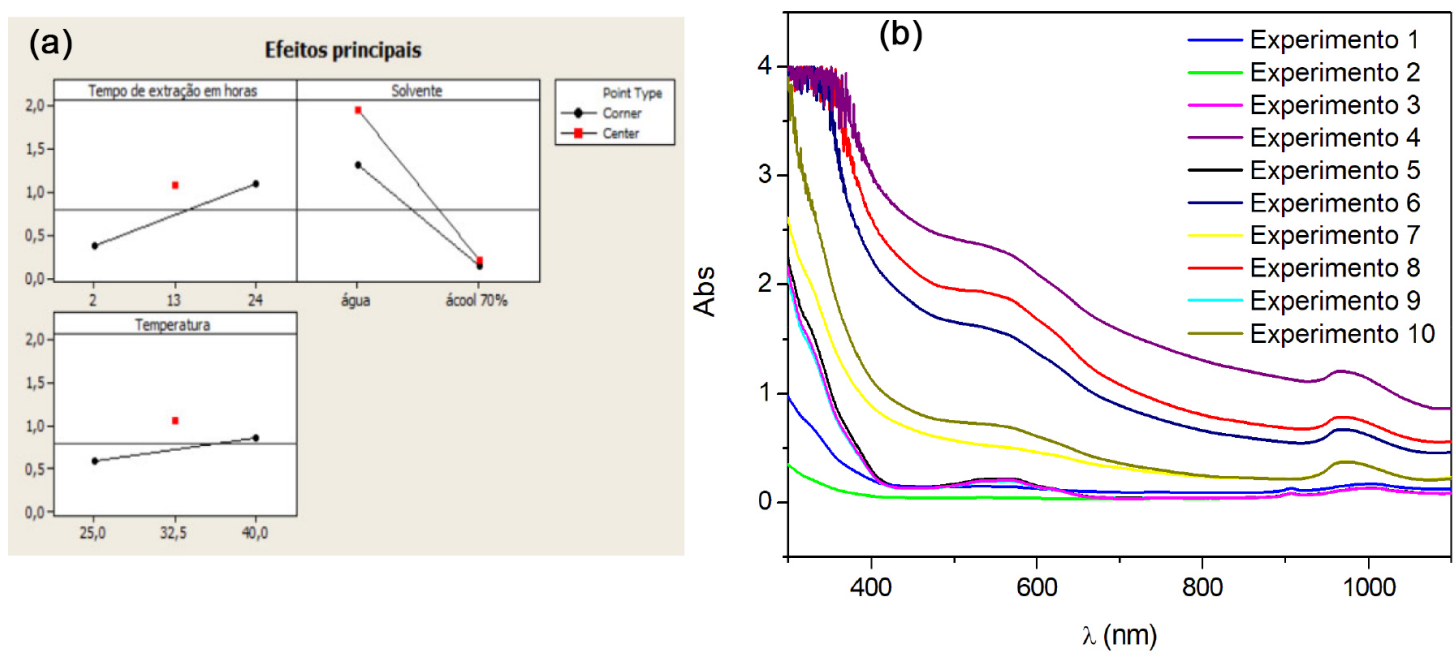

Figura 1. (a) Gráficos dos efeitos principais. (b) Espectros obtidos para cada experimento do planejamento fatorial $2^{3}$ 

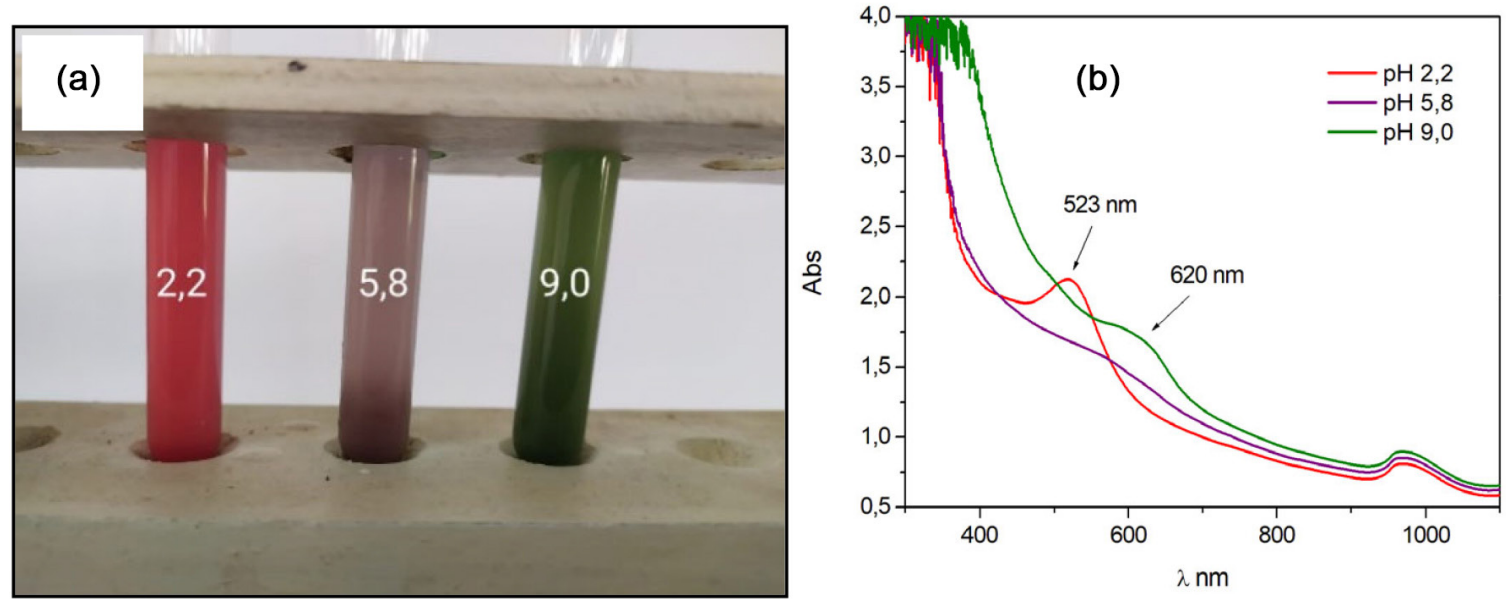

Figura 2. (a) Extrato de feijão, obtido nas condições otimizadas de extração, em solução acidificada (pH 2,2), em pH original do extrato (pH 5,8) e alcalinizada ( pH 9,0). (b) Espectros de absorbância em função do comprimento de onda para cada valor de pH. Os Ajustes de pH das soluções ácidas e básicas foram feitos com soluções de ácido clorídrico e hidróxido de sódio $5 \mathrm{~mol} \mathrm{~L}^{-1}$, respectivamente
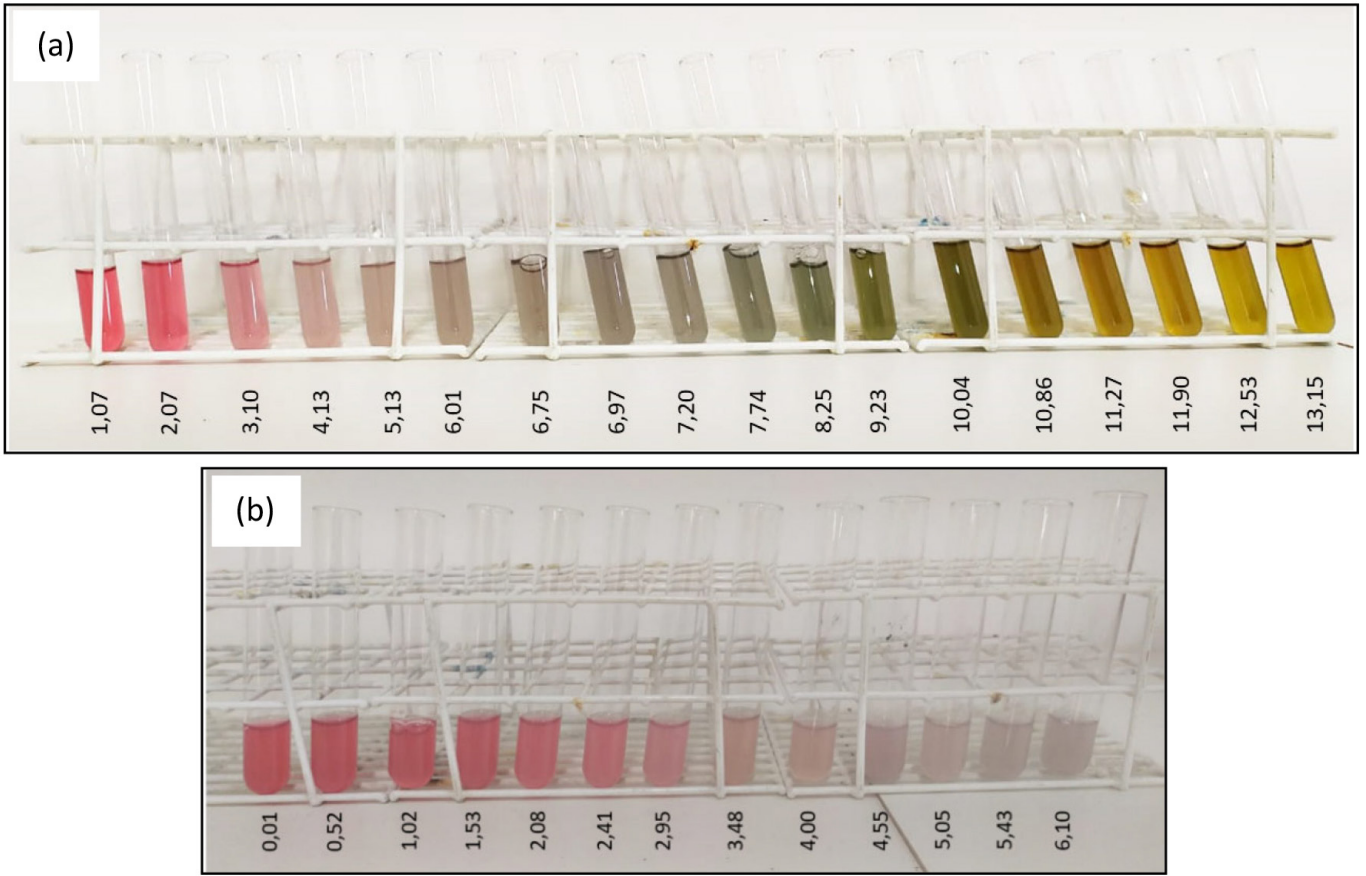

Figura 3. (a) Extratos aquosos de feijão-preto em valores de pH dentro da escala de 1,07 a 13,15. (b) Extratos aquosos de feijão-preto em condições ácidas de $\mathrm{pH}$ com menor intervalo de variação entre os pontos $(0,01$ a 6,10$)$

muito mais intensa e bonita, se aproximando da apresentada na Figura 2(a) que também foi diluída por um fator de 2 . As variações de coloração de extratos naturais em função do $\mathrm{pH}$ foram também observadas por outros autores. Moradi e colaboradores empregaram antocianinas extraídas de cenoura preta para o desenvolvimento de um sensor inteligente de indicador de $\mathrm{pH}$ para alimentos. $\mathrm{O}$ indicador apresentou variações de coloração do vermelho passando para o azul e chegando ao cinza para uma faixa de $\mathrm{pH}$ compreendida entre 2 e $11 .{ }^{8}$ Da Silva e colaboradores avaliaram extratos de diferentes flores e puderam satisfatoriamente relacionar a variação das colorações, tonalidades de vermelho e amarelo, com os valores de $\mathrm{pH}$ das soluções em uma faixa de $1 \mathrm{a} 14$. A capacidade indicadora de $\mathrm{pH}$ foi atribuída às antocianinas presentes nas plantas. ${ }^{9}$ Prietto e colaboradores desenvolveram filmes contendo antocianinas extraídas do feijão-preto e do repolho roxo para serem empregadas como indicadores de $\mathrm{pH}$ e, consequentemente, qualidade de alimentos refrigerados. Os indicadores apresentaram satisfatória variação de coloração, do vermelho ao azul acinzentado, em função do $\mathrm{pH}$ para a faixa de 1 a $10 .^{19}$

As soluções apresentadas na Figura 3(a) foram então analisadas no espectrofotômetro para avaliação da variação das concentrações de HIn e In em função do pH do meio usando os comprimentos de onda já definidos. Os espectros obtidos foram tratados para remoção do sinal de fundo e ajuste de linha de base. Além disso, a faixa compreendida entre 300 e $550 \mathrm{~nm}$ foi removida do espectro, por não apresentar sinal analítico de interesse e assim contribuir para melhor representação do gráfico. A Figura 4(a) mostra os espectros obtidos para estas soluções onde foi possível observar a diminuição da intensidade de Abs no $\lambda=523 \mathrm{~nm}$ com o aumento do $\mathrm{pH}$ e um aumento de intensidade da Abs no $\lambda=620 \mathrm{~nm}$. Também pode-se notar o surgimento de um terceiro pico para os valores de $\mathrm{pH}$ mais elevados em $\lambda=635$. Esse comportamento está relacionado com a mudança estrutural das antocianinas em função do $\mathrm{pH}$ da solução. Tal mudança é visualmente observada pela variação da coloração da 
solução mostrada na Figura 3(a), na qual a espécie com cor vermelha vai diminuindo à medida que a cor verde vai aumentando, em seguida, sua concentração diminui e dá lugar às espécies de cor castanha, ou seja, as antocianinas em sua forma básica. Os três comprimentos de onda máximos observados na Figura 4(a) em aproximadamente $520 \mathrm{~nm}, 620 \mathrm{~nm}$ e $635 \mathrm{~nm}$, sugerem a presença não de duas, mas ao menos de três espécies em equilíbrio na solução. A Figura 4(b) referese aos espectros de absorbância obtidos com as soluções apresentadas na Figura 3(b). Essa maior atenção ao meio ácido justificou-se pela necessidade de mais pontos para a determinação do pKa do indicador.

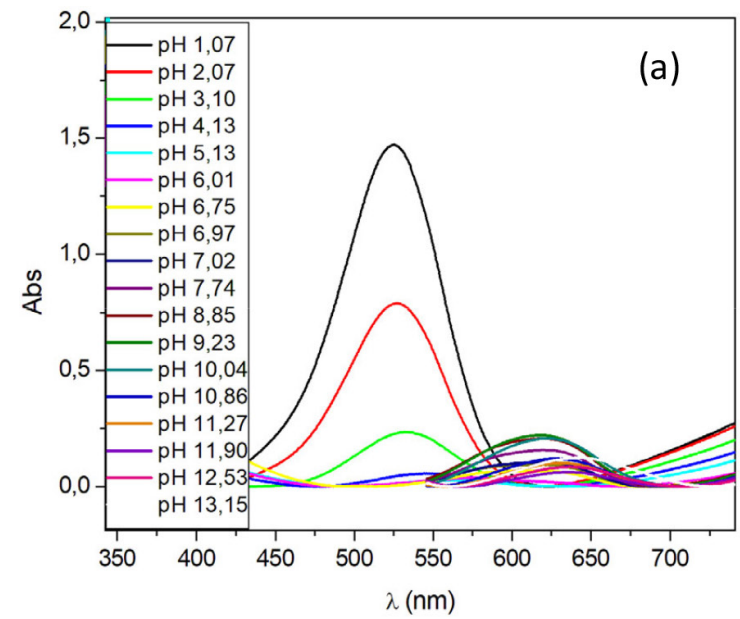

Realizadas as medidas dos extratos em diferentes valores de $\mathrm{pH}$, a intensidade da absorbância foi amostrada e utilizada para plotar um gráfico da Abs em função do $\mathrm{pH}$ em cada um dos comprimentos de onda de maior absorbância. O ponto de inflexão da curva sigmoidal indicou o valor do pKa do indicador. Além dessa análise, também foram utilizados cálculos da primeira e segunda derivadas, no qual o ponto de maior ou menor intensidade para a primeira derivada indica o pKa e o ponto onde cruza o eixo $\mathrm{x}$ da segunda derivada aponta $\mathrm{o}$ pKa. ${ }^{18}$ As Figuras 5(a) e 5(b) referem-se ao comprimento de onda $523 \mathrm{~nm}$, e as Figuras 5(c) e 5(d) ao comprimento de onda $620 \mathrm{~nm}$.

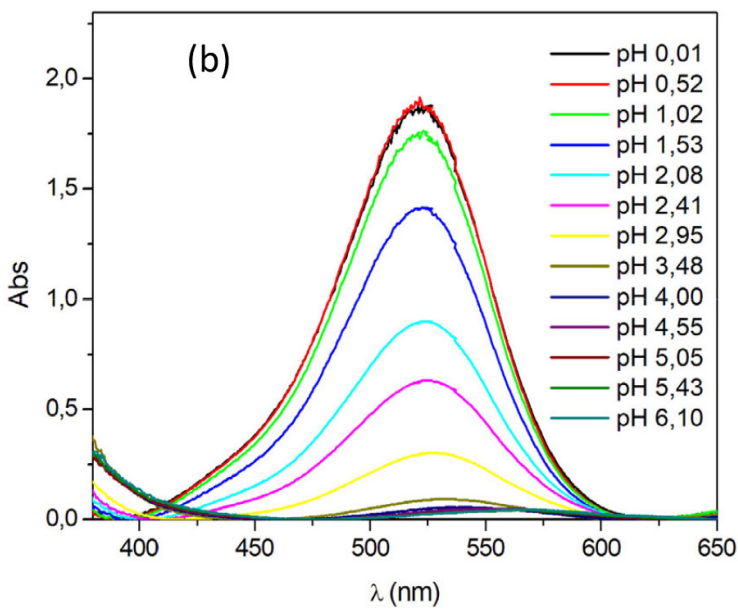

Figura 4. (a) Espectros obtidos para os extratos aquosos de feijão para ampla faixa de $\mathrm{pH}$. (b) Espectros obtidos para os extratos de feijão-preto em condições ácidas de pH com menor intervalo de variação entre os pontos
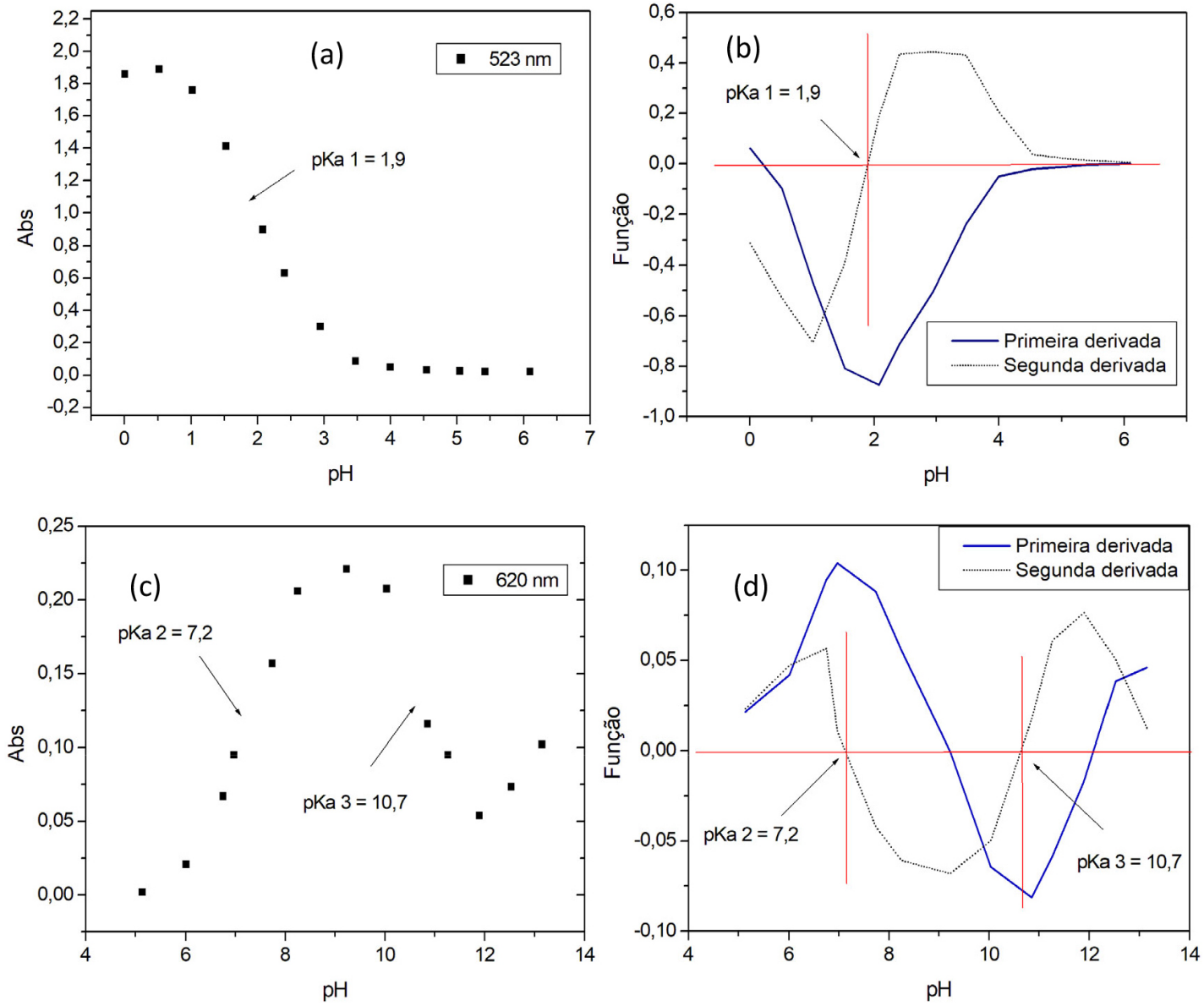

Figura 5. (a) Curva da absorbância em função do pH para $\lambda=523 \mathrm{~nm}$. (b) Gráfico da primeira e segunda derivada para $\lambda=523 \mathrm{~nm}$. (c) Curva da absorbância em função do pH para $\lambda=620 \mathrm{~nm}$. (d) Gráfico da primeira e segunda derivada para $\lambda=620 \mathrm{~nm}$ 
Notou-se que os valores de $\mathrm{pKa}$ determinados podem ser relacionados com a cor das soluções na Figuras 3(a) e 3(b). O pKa 1,9 corresponde ao $\mathrm{pH}$ próximo a 2, ou seja, um equilíbrio químico onde o indicador protonado, que possui cor vermelha, está em mesma concentração que espécies de cor acinzentada, com a estrutura química levemente modificada pelo aumento do $\mathrm{pH}$. Por volta do $\mathrm{pH} 7$, o segundo $\mathrm{pKa}$ foi determinado, ocorrendo a transição para o verde, e novamente em $\mathrm{pH}$ próximo a 11 , outra mudança na coloração da solução pode ser observada. As antocianinas, como descrito anteriormente, pertencem a uma classe de compostos e, dessa forma, neste trabalho, os autores não se preocuparam em identificar cada composto e o equilíbrio químico formado, apenas apontam que, pelo menos, três pKa, relacionados às mudanças estruturais dos componentes do indicador, podem ser determinados e estes estão relacionados à variação de cor do indicador.

A literatura cita várias antocianinas presentes no feijão-preto. Prietto et al. identificaram sete estruturas de antocianinas no extrato do feijão-preto, sendo que a delfinidina-3-O-glucosideo foi a estrutura predominante, representando $40 \%$ do conteúdo total de antocianinas, enquanto a petunidina-3-O-glicosideo, malvidina-3-O-glucosideo, e pelargonidina, representaram 29, 24 e 6\%, respectivamente. Outros compostos identificados no extrato de feijão-preto foram inferiores a $1 \% .{ }^{19}$ Choung et al. determinaram antocianinas em feijões de diferente cores (branco, marrom, preto, vermelho, salpicados com manchas) e verificaram que a quantidade desses compostos dependem muito da cor dos feijões. Relataram que o conteúdo de pelargonidina 3-O-glicosídeo foi maior nos grãos com manchas vermelhas, enquanto a delfinidina 3-O-glicosídeo foi maior nos grãos manchados de preto. ${ }^{20}$

Como descrito na parte inicial desse artigo, o objetivo principal desse trabalho foi a obtenção de um material de fácil utilização para a determinação do $\mathrm{pH}$ de soluções. Sendo assim, primeiramente folhas de papel sulfite foram impregnadas com o indicador, na tentativa de desenvolver um material alternativo ao papel indicador universal. No entanto, esse material mostrou ter baixa molhabilidade e, dessa forma, a velocidade de reação para indicar se uma solução é ácida ou básica foi lenta, inviabilizando o uso deste material. Em seguida, testou-se o papel-filtro qualitativo e o papel-filtro comum, utilizado para coar café. Ambos os materiais apresentaram resultados satisfatórios podendo ser utilizados como superfície de suporte para o indicador e foram carinhosamente apelidados de Papel Tornachal. A Figura 6 apresenta fotos destes materiais em contato com solução $1 \mathrm{~mol} \mathrm{~L}^{-1}$ de ácido clorídrico, ácido acético (vinagre), hidróxido de sódio $1 \mathrm{~mol} \mathrm{~L}^{-1}$ e leite de magnésia (suspensão de hidróxido de magnésio). A Figura 6(a) é referente ao indicador preparado no papelfiltro qualitativo e a Figura 6(b) em papel-filtro para café. Ambos os papéis apresentaram bons resultados, nos quais as soluções ácidas desenvolveram tonalidades rosas e as soluções alcalinas, tons de azul e verde. A única diferença entre os dois materiais ficou por conta da uniformidade e espessura superiores do papel-filtro qualitativo. Pôdese notar ainda uma propriedade interessante do indicador, que foi sua reversibilidade, ou seja, o papel indicador exposto a uma solução ácida, adquirindo coloração rosa, assume uma cor esverdeada quando exposto à solução de hidróxido de sódio (Figura 6(c)).

Uma outra opção ao papel foi a utilização de hastes flexíveis com pontas de algodão comerciais, ou então hastes produzidas com palitos de dente. Ambas as opções são de fácil aquisição e mostraramse práticas para a utilização, uma vez que nenhum outro material, tais como pinças ou bastões de vidro, seriam necessários, bastando apenas tocar a solução a ser testada com as hastes impregnadas com o indicador. Durante o preparo das hastes contendo o indicador, percebeu-se que o algodão demanda um tempo maior para secagem e, dessa forma, notou-se um escurecimento do indicador no algodão, o qual apresentava cores menos intensas. A decomposição do indicador (a)
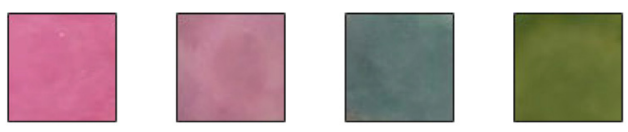

(b)
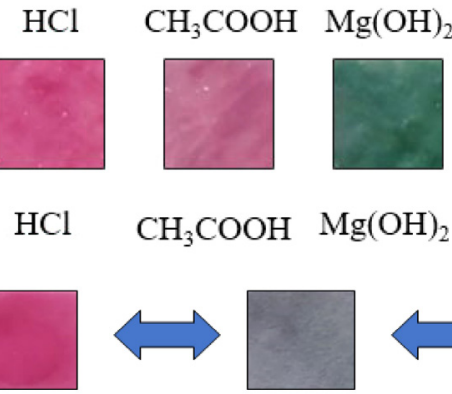

$\mathrm{NaOH}$
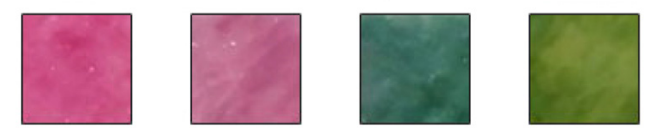

(c)

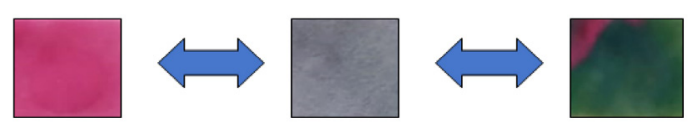

Figura 6. Papel indicador produzido com (a) papel-filtro qualitativo (b) papel-filtro para café. (c) Capacidade de reversibilidade do papel indicador observada com soluções $1 \mathrm{~mol} \mathrm{~L}^{-1}$ de ácido clorídrico e hidróxido de sódio

pode ser atribuída à elevada carga de matéria orgânica, possivelmente proteínas e amido, extraída com as antocianinas, aliado ao fato de nenhum conservante ter sido adicionado. Porém, esse problema foi contornado acelerando a secagem do material com a utilização de um ventilador, reduzindo o tempo de secagem de horas para minutos. Após seco, o material permaneceu estável com suas características iniciais até o presente momento, quatro meses, armazenado em frasco fechado, livre de umidade e luz.

Neste artigo foi apresentado um método otimizado para a extração de antocianinas presentes no feijão-preto. Para tanto, foi realizado o controle rigoroso da temperatura e do tempo de extração, além disso foi utilizada água destilada para o processo. No entanto, esses cuidados dificilmente podem ser tomados em um ambiente escolar, principalmente devido à falta de equipamentos. Dessa forma, foi avaliada também a extração das antocianinas presentes no feijão em uma condição mais condizente com as possibilidades de um professor de ensino básico. As mesmas proporções de feijão e água foram utilizadas, no entanto, foi empregada água da rede de distribuição pública, água de torneira, e um tempo de extração de 12 horas, da noite para o dia, em repouso (condições simplificadas de extração). $\mathrm{O}$ extrato foi muito similar ao obtido pelo processo otimizado, no entanto, menos intenso em coloração (Figura 7(a)). Da mesma forma, os materiais: papel filtro qualitativo, papel filtro para café e algodão foram produzidos e testados. A Figura 7 apresenta os materiais produzidos com (b) hastes flexíveis e (c) palitos de dente. A Figura 7(d) mostra os materiais em contato com solução de ácido clorídrico (ácido muriático), solução de ácido acético (vinagre), suspensão de hidróxido de magnésio (leite de magnésia) e solução de hidróxido de sódio (soda cáustica) da esquerda para a direita, respectivamente. As colorações obtidas usando as soluções de ácido clorídrico (ácido muriático) e de hidróxido de sódio (soda cáustica) foram muito semelhantes às obtidas com as soluções $1 \mathrm{~mol} \mathrm{~L}^{-1}$ de ácido clorídrico e hidróxido de sódio.

Para confirmar a eficiência do extrato de feijão-preto e dos materiais impregnados com o mesmo, papel indicador de $\mathrm{pH}$ universal e soluções tampão pH 4,0, 7,0, 10,0 e 11,2 foram usados. Duas gotas de cada tampão foram adicionadas nos indicadores. A Tabela 2 apresenta fotografias dos indicadores de $\mathrm{pH}$ extraídos do feijão-preto utilizando condições simplificadas de extração e de um papel indicador universal em diferentes condições de $\mathrm{pH}$.

Os resultados apresentados na Tabela 2 mostram que a variação de coloração dos indicadores em contato com as soluções tampão $\mathrm{pH}$ 4,0, 7,0 e 10,0 foi adequada para todos os materiais impregnados e soluções, no entanto, a diferença entre o pH 7,0 e 10,0 foi mais pronunciada para o papel indicador comercial. Entre os valores de 


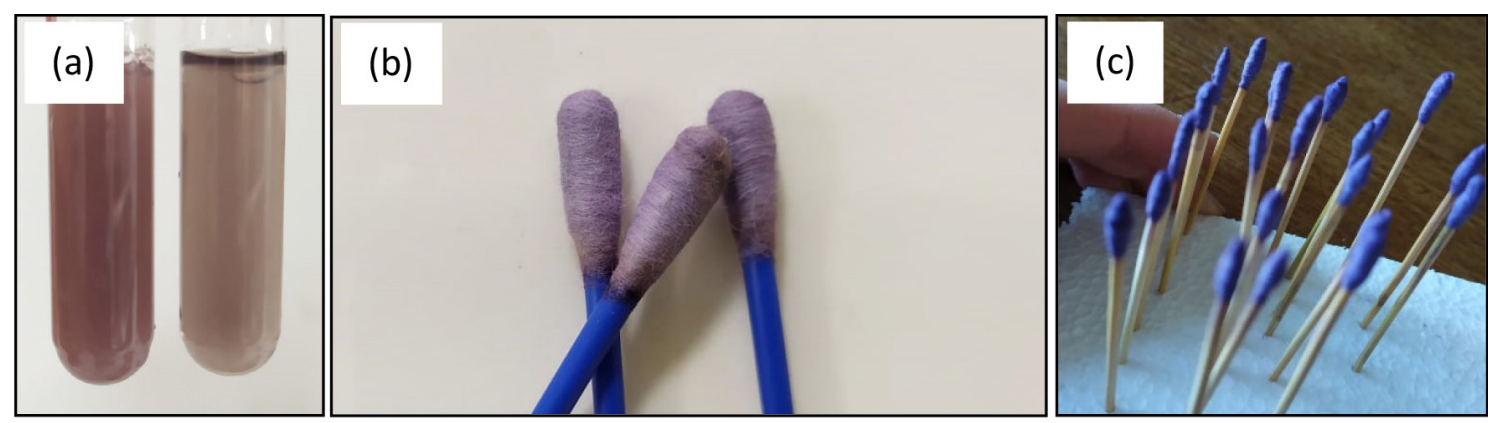

(d)

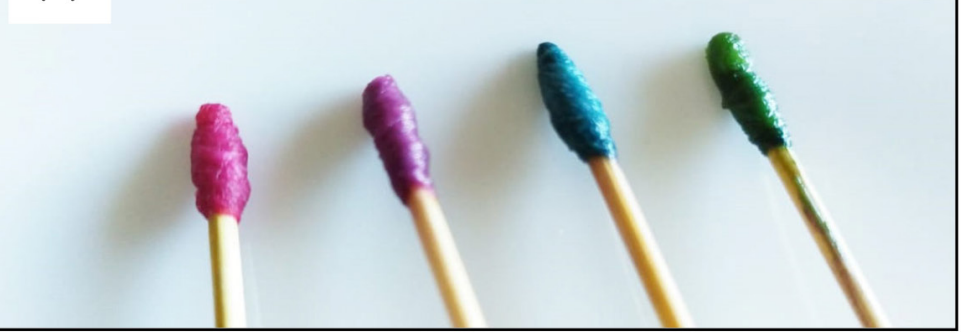

Figura 7. (a) Extratos obtidos com a condição otimizada, solução à esquerda, e condição simples, solução à direita. (b) Indicador impregnado em hastes flexíveis com pontas de algodão. (c) Indicador impregnado em hastes de palito de dente com pontas de algodão. (d) Hastes impregnadas com o indicador molhadas com solução de ácido clorídrico, vinagre, leite de magnésia e solução de hidróxido de sódio de produtos comerciais da esquerda para a direita, respectivamente

Tabela 2. Indicadores de pH extraídos do feijão-preto utilizando as condições simplificadas de extração e papel indicador universal na presença de soluções tampão pH 4,0, 7,0, 10 e 11,2

\begin{tabular}{|c|c|c|c|c|}
\hline \multirow{2}{*}{ Material Indicador } & \multicolumn{4}{|c|}{ Soluções tampão } \\
\hline & $\mathrm{pH} \mathrm{4,0}$ & $\mathrm{pH} \mathrm{7,0}$ & $\mathrm{pH} 10,0$ & pH 11,2 \\
\hline $\begin{array}{l}\text { Extrato de } \\
\text { feijão-preto }\end{array}$ & & & & \\
\hline $\begin{array}{l}\text { Hastes com } \\
\text { algodão }\end{array}$ & & & & \\
\hline $\begin{array}{l}\text { Papel-filtro } \\
\text { qualitativo }\end{array}$ & & & & \\
\hline $\begin{array}{l}\text { Papel-filtro } \\
\text { para café }\end{array}$ & & & & \\
\hline $\begin{array}{l}\text { Papel indicador } \\
\text { de pH universal } \\
\text { comercial }\end{array}$ & & & & \\
\hline
\end{tabular}

Escala do papel indicador de $\mathrm{pH}$ universal comercial
pH 10,0 e 11,2 o indicador de pH comercial não apresentou adequada distinção. Tal resultado já era esperado, visto que a própria escala desse indicador apresenta uma grande semelhança entre as cores para soluções com pH 10, 12 e 14. Por outro lado, os indicadores extraídos do feijão-preto foram eficientes na distinção entre esses dois valores de $\mathrm{pH}$.

\section{CONCLUSÕES}

$\mathrm{O}$ indicador produzido a partir do extrato de feijão-preto nas condições otimizadas de extração apresentou uma boa capacidade de indicação da acidez ou basicidade de soluções e suspensões aquosas, podendo ser utilizado até mesmo para estimar o valor do $\mathrm{pH}$. Os estudos para a determinação do $\mathrm{pKa}$ do indicador revelaram a presença de, pelo menos, três pKa que podem ser relacionados com as cores da solução. $\mathrm{O}$ extrato foi facilmente impregnado em três suportes poliméricos naturais com boas respostas para indicação da acidez ou basicidade. Tanto os materiais produzidos por meio da extração otimizada, quanto os da extração simplificada (sem controle de temperatura, sem agitação e com água de torneira), foram eficientes e indistinguíveis na tonalidade da coloração para os ácidos e bases testados, diferenciando-se apenas na concentração do indicador obtido pela condição otimizada. Uma comparação entre o material impregnado e um papel indicador de $\mathrm{pH}$ universal empregando soluções tampão $\mathrm{pH}$ 4,0, 7,0, 10,0 e 11,2 comprovou a aplicabilidade do material desenvolvido, visto que esse apresentou adequada distinção em sua coloração para as diferentes condições de pH. No que se refere à produção e utilização dos indicadores em experimentos de química, o envolvimento dos alunos no processo desde a etapa inicial pode facilitar muito o desenvolvimento de conceitos, eliminar a monotonia de aulas tradicionais favorecendo assim a aprendizagem significativa. Dessa forma, os conceitos de ácidos e bases, $\mathrm{pH}$ e indicadores podem ser trabalhados no ensino médio. No que diz respeito ao ensino superior, a obtenção e caracterização de indicadores de $\mathrm{pH}$ pode ser ponto de partida para o estudo de técnicas de análise instrumental, no caso a espectroscopia por UV-visível. De forma geral, todos esses conceitos trabalhados, em especial por meio da 
experimentação, abrem portas para a interdisciplinaridade facilmente pensada com a biologia e a física, por exemplo.

\section{REFERÊNCIAS}

1. Brasil; Parâmetros Curriculares Nacionais para o Ensino Médio Ciências da Natureza, Matemática e suas Tecnologias, disponível em http://portal.mec.gov.br/conaes-comissao-nacional-de-avaliacao-daeducacao-superior/195-secretarias-112877938/seb-educacao-basica2007048997/12598-publicacoes-sp-265002211, acessada em setembro de 2021.

2. Paraná; Diretrizes Curriculares da Educação Básica - Química, Secretaria da Educação e do Esporte, 2008.

3. Guimarães, C. C.; Quim. Nova Esc. 2009, 31, 198.

4. Hess, S.; Experimentos de Química com materiais domésticos, $1^{\mathrm{a}} \mathrm{ed}$., Moderna: São Paulo, 2008.

5. Terci, D. B. L.; Rossi, A. V.; Quim. Nova 2002, 25, 684.

6. Nagashima, L. A.; Pires, M. M. Y.; Zanatta, S. C.; Coletânea de Atividades Experimentais, $1^{\mathrm{a}}$ ed., Editora Gráfica Paranavaí: Paranavaí, 2013.

7. Soares, M. H. F. B.; Cavalheiro, É. T. G.; Antunes, P. A.; Quim. Nova 2001, 24, 408 .

8. Moradi, M.; Tajik, H.; Almasi, H.; Forough, M.; Ezati, P.; Carbohydr. Polym. 2019, 222, 115030.

9. Silva, J.; Martins, R.; Bernardi, F.; Santos, C.; Nicolini, K.; Nicolini, J.; Quim. Nova 2020, 43, 231.
10. Lucas, M.; Chiarello, L. M.; Silva, A. R. da; Barcellos, I. O.; Experiências em Ensino de Ciências 2013, 8, 61.

11. Alizadeh-Sani, M.; Tavassoli, M.; Mohammadian, E.; Ehsani, A.; Khaniki, G. J.; Priyadarshi, R.; Rhim, J.-W.; Int. J. Biol. Macromol. 2021, 166, 741.

12. Etxabide, A.; Kilmartin, P. A.; Maté, J. I.; Food Control 2021, 121 , 107645.

13. Okumura, F.; Soares, M. H. F. B.; Cavalheiro, É. T. G.; Quim. Nova 2002, 25, 680 .

14. Soares, M. H. F. B.; Silva, M. V. B.; Cavalheiro, É. T. G.; Ecletica Quim. 2001, 26, 225.

15. Strack, D.; Wray, V.; In Methods in Plant Biochemistry, Harborn, J. B., ed.; Academic Press Limited: San Diego, 1989, cap. 9.

16. Kapilraj, N.; Keerthanan, S.; Sithambaresan, M.; J. Chem. 2019, 2019, 1.

17. Takikawa, A. Y.; Trabalho de conclusão de curso, Universidade Tecnológica Federal do Paraná, Brasil, 2014.

18. Previdello, B. A. F.; Carvalho, F. R. de; Tessaro, A. L.; Souza, V. R. de; Hioka, N.; Quim. Nova 2006, 29, 600.

19. Prietto, L.; Mirapalhete, T. C.; Pinto, V. Z.; Hoffmann, J. F.; Vanier, N. L.; Lim, L.-T.; Dias, A. R. G.; Zavareze, E. da R.; LWT - Food Sci. Technol. 2017, 80, 492.

20. Choung, M. G.; Choi, B. R.; An, Y. N.; Chu, Y. H.; Cho, Y. S.; J. Agric. Food Chem. 2003, 51, 7040 . 